\title{
Secondhand philosophy
}

\section{Lorri Neilsen Glenn, Mount Saint Vincent University}

t's a day to listen to country music at the local thrift store, wearing the soft corduroy shirt with the funky smell we don't want to wash out. A day to pick through the racks and overhear the young woman with the wail in her voice talk about her night course. I was kicked out of the other one, she tells the large woman sitting by the counter who is sorting shirts into long sleeves and short; I was kicked out for-what did they call it?--confidentiality. I said things out loud I shouldn't have. I need to learn to write it down or keep it in my head.

It's a day for separating sleeves by size, shirts by colour, for wondering where to draw the lines that make us, between what we think and what we tell. To wonder about the detours - the aisle that holds red and orange polyester dresses with bent foam shoulder pads that someone once wore to a dance, perhaps, felt beautiful. Or the tales that fell apart, the two-chord song that urged us to ride our horse, darling, to dream that dream. Those truths that won't be gentled into story, cannot slip easily over our hips. Bright and broken buttons we wear out loud. 


\section{Advice to a Child}

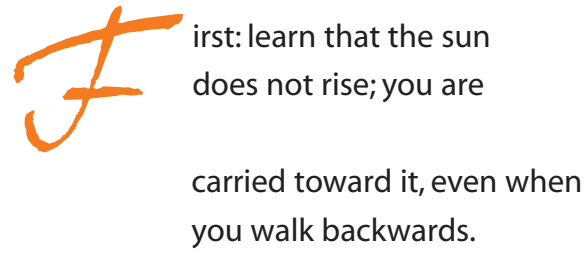

Bed, window, house, moon:

These form the binding

of all the words you will read.

Blood is the way you pray,

and you will never understand

it all, but its holy ghost

will show you constellations. You are

as singular as a shadow:

carry water in a bowl painted

by old hands, and showers.



Lorri Neilsen Glenn has written poetry collections that include All the Perfect Disguises, Saved String, and Combustion (2007, Brick Books). Her work has appeared in Arc, Prairie Fire, CV2, The Malahat Review, The Antigonish Review, Event, Grain, and anthologies such as White Ink, Nth Position, Dropped Threads 3, Common Magic, among others. As an ethnographer, she has written several books in the field of literacy as well as works of creative nonfiction. She is Poet Laureate of Halifax for 20052009 and currently Professor in literacy at Mount Saint Vincent University. 